\title{
MiR-148a-3p Regulates the Invasion and Odontoblastic Differentiation of Human Dental Pulp Stem Cells via the Wnt1/ $\beta$-Catenin Pathway
}

\author{
Qiong Li, Lei Huang \\ Department of Oral and Maxillofacial Surgery, Fingmen NO.1 People's Hospital, Fingmen, China
}

\begin{abstract}
Background and Objectives: MiR-148a-3p has been reported to regulate the differentiation of marrow stromal cell osteoblast. In this study, whether miR-148a-3p regulated the odontoblastic differentiation of human dental pulp stem cells (hDPSCs) or not was explored.

Methods and Results: The hDPSCs were isolated and identified via flow cytometry. Targets of miR-148a-3p were identified via bioinformatics and dual-luciferase reporter assay. After the cell was cultured in the odontogenic differentiation medium or infected, cell viability, invasion, and odontoblastic differentiation were detected via MTT, transwell, and Alizarin Red S staining, respectively. The miR-148a-3p, Wnt1, $\beta$-catenin, DSPP, DMP-1, RUNX2, OCN, and Smad4 expressions were determined by RT-qPCR and Western blot. The hDPSCs odontoblastic differentiation downregulated the miR-148a-3p expression and upregulated Wntl expression. Wntl was determined as the target for miR-148a-3p. MiR-148a-3p mimic and siWntl suppressed the cell viability, invasion, and odontoblastic differentiation of hDPSCs and inhibited the Wnt1, $\beta$-catenin, DSPP, DMP-1, RUNX2, OCN, and Smad4 expressions. In contrast, miR-148a-3p inhibitor and overexpressed Wntl promoted the cell viability, invasion, and odontoblastic differentiation of hDPSCs, and upregulated the Wnt1, $\beta$-catenin, DSPP, DMP-1, RUNX2, OCN, and Smad4 expressions. Also, miR-148a-3p mimic and inhibitor reversed the effects of Wntl overexpression and siWntl.

Conclusions: MiR-148a-3p modulated the invasion and odontoblastic differentiation of hDPSCs through the Wnt1/ $\beta$ catenin pathway.
\end{abstract}

Keywords: Human dental pulp stem cells, miR-148a-3p, Odontoblastic differentiation, Wnt1, $\beta$-catenin

Received: July 21, 2020, Revised: April 20, 2021,

Accepted: May 17, 2021, Published online: August 31, 2021

Correspondence to Lei Huang

Department of Oral and Maxillofacial Surgery, Jingmen NO.1 People's Hospital, No.168 Xiangshan Avenue, Duodao District, Jingmen 448000, China

Tel: +86-0724-8606551, Fax: +86-0724-2305120

E-mail: huanglei_lhu@163.com

(a) This is an open-access article distributed under the terms of the Creative Commons Attribution Non-Commercial License (http://creativecommons.org/ licenses/by-nc/4.0/), which permits unrestricted non-commercial use, distribution, and reproduction in any medium, provided the original work is properly cited.

Copyright (C) 2021 by the Korean Society for Stem Cell Research

\section{Introduction}

Pulpitis and periapical periodontitis are the most frequently diagnosed dental diseases $(1,2)$. Affected by the special histo-physiological characteristics of pulp, it is difficult for the pulp to recover after being damaged (3). At present, root canal treatment is the main strategy for treating pulpitis and periapical periodontitis by applying artificial materials, such as glue tip and paste, to fill the empty root canal for replacing the damaged pulp tissues after cleaning and disinfecting the root canal $(1,4)$. Loss of pulp will reduce blood vessels and nerves, nutrition of the teeth and stress sensing ability. Moreover, teeth losing protection from immune system will increase dentin fra- 
gility and tooth fracture $(5,6)$. Therefore, new strategies should be developed to regenerate the original tissues and restore the dental pulp properties.

Human dental pulp stem cells (hDPSCs), a type of fibroblast and derived from mesenchymal tissue, are regarded to be ideal seed cells for the therapy of pulp regeneration owing to their multidirectional differentiation potential $(7,8)$. hDPSCs could differentiate into osteoblasts, nerve cells, adipocytes, and odontoblasts with great ability to proliferate and differentiate $(3,6,9,10)$. However, the regulatory mechanism of hDPSCs differentiation is still unclear and needs more exploration, which limits the clinical application of hDPSCs.

MicroRNAs (miRNA) play crucial roles in many biological processes (11). Increasing research and evidence have proved that anomalous levels of miRNAs are closely associated with the genesis and progression of different types of diseases, and they further regulate the biological function of various cells, including hDPSCs $(11,12)$. For example, miR-125a-3p is found to have the ability to regulate the odontoblastic differentiation of hDPSCs by targeting Fyn (13). Low-expression of miR-224-5p could enhance the migration and proliferation of hDPSCs (14). miR-224-5p could protect hDPSCs from apoptosis through targeting Racl (5). miR-140-5p also regulates the differentiation of hDPSCs into the odontoblasts (2). Abnormal expression of miR-148a-3p is also widely discovered to be existed in various disease and cancer, such as ovarian cancer, acute pancreatitis, and gastric cancer (15-17). MiR-148a-3p also regulates the capacities of different kinds of cells to proliferate, invade, and differentiate $(15,16)$. What's more, it has been confirmed in an existing research that miR-148a-3p can modulate the osteoblast differentiation of marrow stromal cells (18), which makes us wonder whether miR-148a-3p also modulates the differentiation ability of hDPSCs to odontoblasts.

Therefore, the purpose of the current study was to explore the role of miR-148a-3p in odontoblastic differentiation of hDPSCs.

\section{Materials and Methods}

\section{Tissue samples and ethics statement}

The third molars were gathered from 10 patients (14 22 years old) who underwent tooth extraction at Jingmen NO.1 People's Hospital between March 2019 and May 2019. The study had been approved by the Ethics Committee of Jingmen NO.1 People's Hospital (Z20190223Y) and all patients had signed a written informed consent and agreed that their tissues would be used for clinical research.

\section{hDPSCs isolation and culture}

hDPSCs were isolated from the collected third molars. In brief, pulp was firstly taken out and digested by collagenase type I (17100-017, Invitrogen, Carlsbad, CA, USA) for 1 hour (h) at $37^{\circ} \mathrm{C}$. Then, after the digestion, the solution was centrifuged $(900 \times \mathrm{g})$ for 5 minutes (min) and the sediment was seen as hDPSCs. Finally, hDPSCs were grown in DMEM (11995065, Gibco, Waltham, MA, USA) with the supplementation of $10 \%$ (v/v) FBS (16140071, Gibco, USA), $10 \mathrm{U} / \mathrm{ml}$ penicillin (DEPENE01, Demeditec, Germany), and 1\% penicillin-streptomycin (P/S; 15070063, Gibco) at a $37^{\circ} \mathrm{C}$ atmosphere with $5 \% \mathrm{CO}_{2}$. The medium of hDPSCs was changed every three days (d) and the morphology of hDPSCs was observed under an optical microscope (DM4M, Leica, Solms, Germany) every day.

\section{Flow cytometry}

Flow cytometry were used for identification of phenotype of the hDPSCs. In brief, the cells were harvested and re-suspended in FACS buffer (MB-089-0500, Dickinson Biosciences, Philadelphia, PA, USA) and incubated with primary antibodies for $25 \mathrm{~min}$ at $4^{\circ} \mathrm{C}$ : CD44 (ab6124, Abcam, Cambridge, MA, USA), CD73 (ab202122, Abcam, USA), CD29 (MAB17781, R\&D System, Minneapolis, MN, USA), CD31 (ab9498, Abcam, USA), CD34 (ab81289, Abcam, USA), and CD45 (ab10558, Abcam, USA). The cells were then incubated with goat anti-rabbit IgG (ab102291, Abcam, USA) for $15 \mathrm{~min}$. Finally, the cells were analyzed using a FACSCaliburTM flow cytometer which was brought from the BD Biosciences (San Jose, CA, USA).

\section{Odontoblastic differentiation of hDPSCs}

From the fourth passages, hDPSCs were grown in the differentiation medium (19) (DMEM medium with FBS (15\%), $\beta$-glycerophosphate (10 mmol/l; 13408-09-08, APExBIO, Houston, TX, USA), $\alpha$-ascorbic acid $(50 \mathrm{mg} / \mathrm{ml}$; 89924-69-6, APExBIO, USA), dexamethasone (10 nmol/l; 50-02-2, APExBIO, USA), glutamine $(0.292 \mathrm{mg} / \mathrm{ml}$; 5959-955 , APExBIO, USA), and $1 \% \mathrm{P} / \mathrm{S}$ ) for $14 \mathrm{~d}$.

\section{Culture of HEK 293T}

HEK 293T cells (CRL-11268) were brought from ATCC (Rockville, MD, USA) and grown in DMEM containing $10 \% \mathrm{FBS}$ at a $37^{\circ} \mathrm{C}$ atmosphere with $5 \% \mathrm{CO}_{2}$. 293T cells were only used for the construction of lentivirus.

\section{Lentivirus construction}

The primer for Wntl overexpression sequence was listed: F: 5'-AGGTTCCATCGAATCCTGCAC-3', R: 5'-CAT 
CTCGGAGAATACGGTCGT-3'. The primer to get siRNA target for Wnt1 (siWnt1, 5'-GTCGAGAAACGGCGTTTA TCTTC-3'). The Wntl overexpression sequence was ligated into pLJM1 plasmid vector (60908-4538, TIANDZ, Beijing, China) by $2 \times$ EasyTaq SuperMix (AS111-11, TRANS, Beijing, China) respectively. siWntl sequence was ligated into pLKO.1-TRC plasmid vector (BiovectorLKO.1-TRC, Biovector NTCC Inc., Beijing, China, http://www.googbio.com/product/127.html) by $2 \times$ EasyTaq SuperMix respectively. Then these ligated-vectors $(10 \mu \mathrm{l})$ were mixed with $50 \mu 1$ competent cells and uniformly coated on the LB medium (SJH0116, REGAL, Shanghai, China) and incubated together for $16 \mathrm{~h}$ at $37^{\circ} \mathrm{C}$. After the colonies on the medium were selected, the TIANprep Mini Plasmid Kit (DP103-03, TIANGEN, Beijing, China) was applied for the extraction of plasmids (The pLJM1 plasmid vector and pLKO.1-TRC plasmid vector without any target sequence was used as negative control).

After we collected the target plasmids, 293T cells were placed into a $15 \mathrm{~cm}$ dish $\left(1.2 \times 10^{7}\right.$ cells in $20 \mathrm{ml}$ complete medium) and grown to a $70 \%$ confluence. Then the target plasmids and viral packaging plasmids (psPAX2 (VT1444, YouBio, Changsha, China) and pMD2.G (VT1443, YouBio, China) were co-transfected into the 293T cells through Lipofectamine 2000 reagent (11668-019, Invitrogen, USA). After the incubation for $8 \mathrm{~h}$, the medium contained overexpression plasmids and viral packaging plasmids were replaced with the fresh complete medium and cells were cultured for another $48 \mathrm{~h}$. Then the supernatant of culture medium was filtered with 0.45 filter (342414, Beckman, CA, USA), the lentiviral solution was centrifuged for 15 $\min$ at $4^{\circ} \mathrm{C}(4,000 \times \mathrm{g})$ to concentrate the lentivirus, followed by the collection.

\section{Lentivirus infection}

Before the infection, $2 \mathrm{ml}$ complete medium with $1.0 \times 10^{6}$ hDPSCs were added into each well of 6-well plates and hDPSCs were grown to a $70 \%$ confluence. The complete medium was replaced with the one containing DMEM with FBS, and the cells were further incubated for $4 \mathrm{~h}$. Then the lentivirus was used to infect the cells for $6 \mathrm{~h}$. Finally, the medium contained lentivirus was changed with complete medium for cell culture, and the cells were further cultured for further $48 \mathrm{~h}$.

\section{Liposomes transfection}

The miR-148a-3p mimic (miR1150109120446-1-5), mimic control (miR1N0000001-1-5), miR-148a-3p inhibitor (miR20000243-1-5), and inhibitor control (miR2N00000011-5) were obtained from RIBOBIO (Guangzhou, China).
Before the infection, $2 \mathrm{ml}$ complete medium with $1.0 \times 10^{6}$ hDPSCs were added into each well of 6-well plates and grown to a $70 \%$ confluence. Then the complete medium was replaced with the one containing DMEM with FBS, and the cells were further incubated for $4 \mathrm{~h}$. Besides, 2 $\mu \mathrm{g}$ of mimic or inhibitor were diluted with $100 \mu \mathrm{l}$ Opti-MEM (11058021, Gibco, USA) were incubated with $100 \mu 1$ Opti-MEM which containing $3 \mu 1$ Lipofectamine 2000 reagent (11668-019, Invitrogen, USA). Then the incubated buffer was added into the 6-well plates to incubate the cells for another $6 \mathrm{~h}$. Then the medium in the 6-well plates was refreshed with DMEM medium for the final $48 \mathrm{~h}$ of culture. Finally, the transfected-cells were harvested for later use.

\section{Bioinformatics and dual-luciferase reporter assay}

TargetScan 7.2 was applied to predict the target gene of miR-148a-3p, and dual luciferase reporter gene system was used to verify the target relation. The wide-type sequence of Wntl (Wnt1-WT) (5'-CGGGAGACCCCTTGTT GCACTGC-3') and mutant sequence (Wnt1-MUT) (5'CGGGAGACCCCTTGTACACTACA-3') were cloned into the luciferase Vectors (E1330) which were brought from the Promega (Madison, WI, USA). $300 \mu 1$ medium with $3.0 \times 10^{4} 293 \mathrm{~T}$ cell were placed into 48 -well plates and cells were grown overnight. Then the $293 \mathrm{~T}$ cells were transfected with the vectors of Wnt1-WT and Wnt1-MUT and miR-148a-3p mimic or inhibitor by Lipofectamine 2000 reagent for $48 \mathrm{~h}$. After being administrated with the working kit (ab228530, Abcam, USA), the cells were added into the SpectraMax reader (Molecular Devices, Shanghai, China) for the measurement on the luciferase activity.

\section{MTT assays}

MTT (B7777, APExBIO) was used to test the cell viability. After infection or transfection, the concentration of hDPSCs was adjusted to $1.0 \times 10^{4}$ cells $/ \mathrm{ml}$, and then $100 \mu 1$ cell suspensions were added into 96 -well plates $\left(10^{3}\right.$ cells/well $)$. After growing for $24 \mathrm{~h}$, MTT reagent $(0.5 \mathrm{mg} / \mathrm{ml})$ (B7777, APExBIO, USA) was used to further incubate the cell for $4 \mathrm{~h}$. Then, the MTT solution was discarded and $100 \mu 1$ DMSO (ST038, Beyotime, Shanghai, China) was added to each well. Finally, the 96-well plates were placed into a microplate reader (imark, Bio-Rad, Hercules, CA, USA) to read the cells absorbance in each well under $570 \mathrm{~nm}$.

\section{Transwell assays}

Transwell chambers (354234) which used for invasion detection were bought from Corning Life Sciences (NY, USA). In brief, after infection or transfection, $0.2 \mathrm{ml}$ 
non-serum medium with hDPSCs $\left(1.5 \times 10^{5}\right)$ were placed into the chambers which were embedded into the well of 24-well plates. After each well of the 24-well plates was added with completely medium and the cells were incubated for $48 \mathrm{~h}$, the inner layer of the chambers was wiped. Finally, the cells in outer layer of the chamber were stained with crystal violet (C110704, Aladdin, Shanghai, China) at room temperature for $15 \mathrm{~min}$. The areas on each outer layer of the chamber were observed under an optical microscope (DM4M, Leica, Solms, Germany). Image J 1.8.0 software was used to count the number of the cells invaded from inner layer to outer layer of the chamber.

\section{Alizarin red staining}

Alizarin red staining was performed by the alizarin red S staining kit (0223, ScienCell, Carlsbad, CA, USA). After the infection or transfection and being washed with PBS, hDPSCs were fixed with 97\% ethanol (E111992-12X, Aladdin, Shanghai, China) for $10 \mathrm{~min}$. Finally, the fixed cells were further dyed with Alizarin red for $30 \mathrm{~min}$ at $37^{\circ} \mathrm{C}$ and observed under an optical microscope (DM4M, Leica, Solms, Germany).

\section{RNA extraction and RT-qPCR}

TRIzol reagent (15596, Invitrogen, USA) was applied to extract the total RNA following the instructions. In brief, after infection, TRIzol was used to lyse the hDPSCs. The lysis was then mixed with chloroform (C805077, Macklin, Shanghai, China) in a centrifugal tube (615001, Nest, Wuxi, China) and centrifuged $(14,000 \times \mathrm{g})$ for $20 \mathrm{~min}$. After the collection of the supernatant, the same volume of isopropanol (H822173, Macklin, China) was mixed with the supernatant, followed by the centrifugation for $5 \mathrm{~min}$ $(14,000 \times \mathrm{g})$. RNA sediment was then collected. For miRNA, it was extracted using EasyPure miRNA Kit
(ER601-01, TransGen Biotech, Beijing, China) (https:// www.transgen.com.cn/rna/372.html?renqun youhua=1844663). In brief, after infection, the hDPSCs were lysed by lysis buffer which was contained in the kit. $200 \mu 1$ chloroform was added into the cells, followed by the process of 1-min severe shaking and 5-min resting. Then the hDPSCs were centrifuged $(13,400 \times \mathrm{g})$ for $20 \mathrm{~min}$ and the supernatant was collected and mixed with ethanol for further centrifugation $(15 \mathrm{~min}, 13,400 \times \mathrm{g})$. Finally, the miRNA sediment was collected.

Then, the total RNAs and miRNAs were synthesized into the cDNA using the cDNA Synthesis kit (AE301-02, TransGen Biotech) in light of instructions. The last step was to amplify the cDNAs using PerfectStart Green qPCR SuperMix (AQ601-01, TransGen Biotech) in QuantStudio6 system (Applied Biosystems, Foster City, CA, USA), and the program was set at $94^{\circ} \mathrm{C}$ for 30 seconds (s), $94^{\circ} \mathrm{C}$ for $30 \mathrm{~s}$ for 40 cycles, $60^{\circ} \mathrm{C}$ for $30 \mathrm{~s}$ for 40 cycles. RNA was quantified by $2^{-\triangle \Delta \mathrm{CT}}$ method. The primers involved in this research were exhibited in Table 1.

\section{Western blot assays}

NP-40 buffer (P0013F, Beyotime, China) was first used to lyse hDPSCs to obtain the total protein. Then BCA kit (P0009, Beyotime, China) was used to detect the concentrations of total protein. $30 \mu \mathrm{g}$ protein was separated inside the SDS-PAGE gels (P0052A, Beyotime, China) and transferred to the surface of the $\mathrm{NC}$ membranes (HTS112M, MilLipore, St Louis, MO, USA), followed by the membranes were blocked with no-fat milk at a concentration of $5 \%$. Then the membrane was incubated with first antibodies for $16 \mathrm{~h}$ : Wntl (1 : 1,000, 41kD, ab15251, Abcam, US), $\beta$-catenin (1 : 1,000, 95kD, abl6051, Abcam, USA), DSPP (1:1,000, 131kD, SAB1304988, SigmaAldrich, St Louis, MO, USA), DMP-1 (1 : 1,000, 55kD, ab103203, Abcam, US), OCN ( $1: 1,000,11 \mathrm{kD}$, ab93876,

Table 1. RT-qPCR primers

\begin{tabular}{|c|c|c|}
\hline Target gene & Forward primers, $5^{\prime}-3^{\prime}$ & Reverse primers, $5^{\prime}-3^{\prime}$ \\
\hline miR-148a-3p & TCAGTGCACTACAGAACTTTGT & GAATACCTCGGACCCTGC \\
\hline Wnt1 & CGATGGTGGGGTATTGTGAAC & CCGGATTTTGGCGTATCAGAC \\
\hline DSPP & TTTGGGCAGTAGCATGGGC & ССАTCTTGGGTATTCTCTTGCСT \\
\hline DMP-1 & CTCCGAGTTGGACGATGAGG & TCATGССТGСАСТGTTСАTTC \\
\hline RUNX2 & TGGTTACTGTCATGGCGGGTA & TCTCAGATCGTTGAACCTTGCTA \\
\hline $\mathrm{OCN}$ & САСТССТСGСССТАTTGGC & СССТССТGСТTGGAСАСАAAG \\
\hline Smad4 & СTCATGTGATCTATGCCCGTC & AGGTGATACAACTCGTTCGTAGT \\
\hline$\beta$-catenin & AAAGCGGCTGTTAGTCACTGG & CGAGTCATTGCATACTGTCCAT \\
\hline U6 & CTCGCTTCGGCAGCACA & AACGCTTCACGAATTTGCGT \\
\hline GAPDH & AGGTCGGTGTGAACGGATTTG & GGGGTCGTTGATGGCAACA \\
\hline
\end{tabular}


Abcam, USA), RUNX2 (1 : 1,000, 60kD, ab23981, Abcam, USA), Smad4 (1:1,000, 60kD, ab40759, Abcam, USA), and GAPDH (1:1,000, 36kD, ab181602, Abcam, USA). Then the membranes were incubated with the matching goat anti-rabbit IgG (1 : 5,000, ab205718, Abcam, USA) or goat anti-mouse $\operatorname{IgG}(1: 5,000$, ab205719, Abcam, USA) for $2 \mathrm{~h}$ at room temperature. The membranes were incubated with developer solution (P0019, Beyotime, China) for $1 \mathrm{~min}$ at normal room temperature. Last, the signal of the membranes and the densitometric analysis of the protein were detected under the Image $\mathrm{Lab}^{\mathrm{TM}}$ Software 3.0 (Bio-Rad, USA).

\section{Statistical analysis}

One-way ANOVA or student's t-test were used for the analysis of all the data under SPSS software (version 18.0), and Dunnett's post-hoc test was utilized for the post-hoc tests. Statistical data presented as mean \pm SD. $p<0.05$ indicated the data were statistically significant.

\section{Results}

\section{hDPSCs was isolated and identified}

We firstly isolated hDPSCs from the normal human third molars, which were further expanded and passaged. As shown in Fig. 1A, on the day 7, the primary cells adhered to each other and exhibited long spindle shape, showing the characteristics of hDPSCs (2). Then, the hDPSCs were identified by flow cytometry for cell surface markers $(20,21)$, and $96.77 \%$ of the cells were CD44-positive, $98.74 \%$ were CD73-positive, and 90.19\% were CD29-positive; whereas $0.11 \%$ of the cells were CD31-negative, $0.13 \%$ were CD34-negative, and $0.44 \%$ were CD45-negative (Fig. 1B). Therefore, hDPSCs were successfully isolated, identified and cultured.

\section{MiR-148a-3p expression was decreased and that of Wntl was increased in hDPSCs after the differentiation of hDPSCs}

After cells were cultured in odontogenic differentiation medium for $14 \mathrm{~d}$, the formation of calcium nodules of hDPSCs was increased, which indicated that the odontogenic differentiation in hDPSCs was increased (Fig. 2A).
A

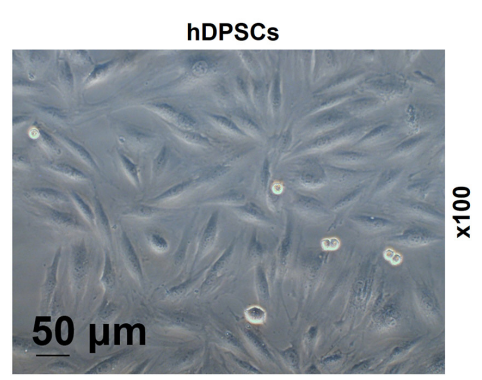

$\frac{8}{x}$
B
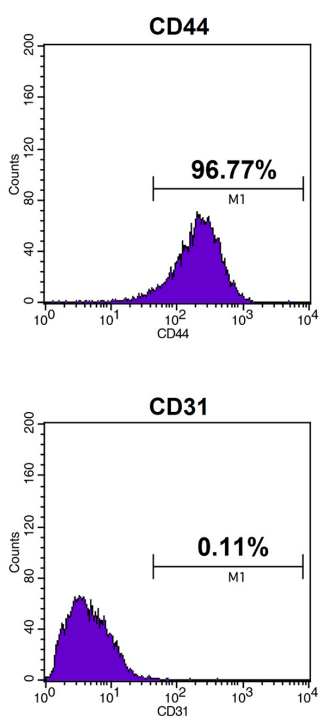

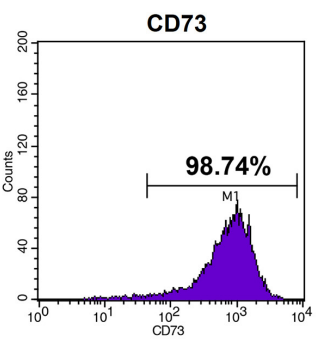

CD34

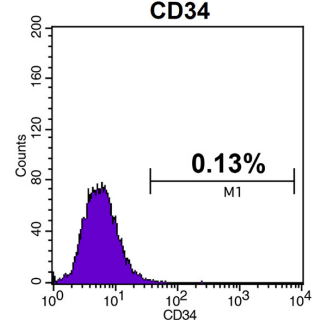

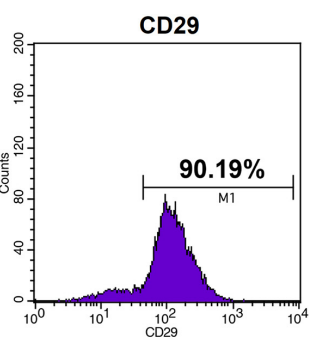

CD45

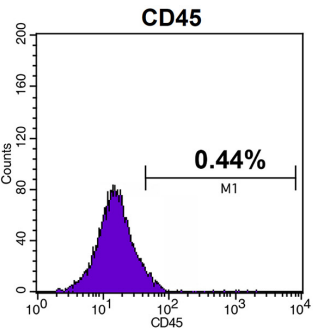

Fig. 1. hDPSCs was isolated and identified. (A) Cell morphology of hDPSCs was observed. (B) The levels of the biomarkers in hDPSCs were detected by flow cytometry. All experiments were conducted in triplicate (hDPSCs: human dental pulp stem cells). 
A
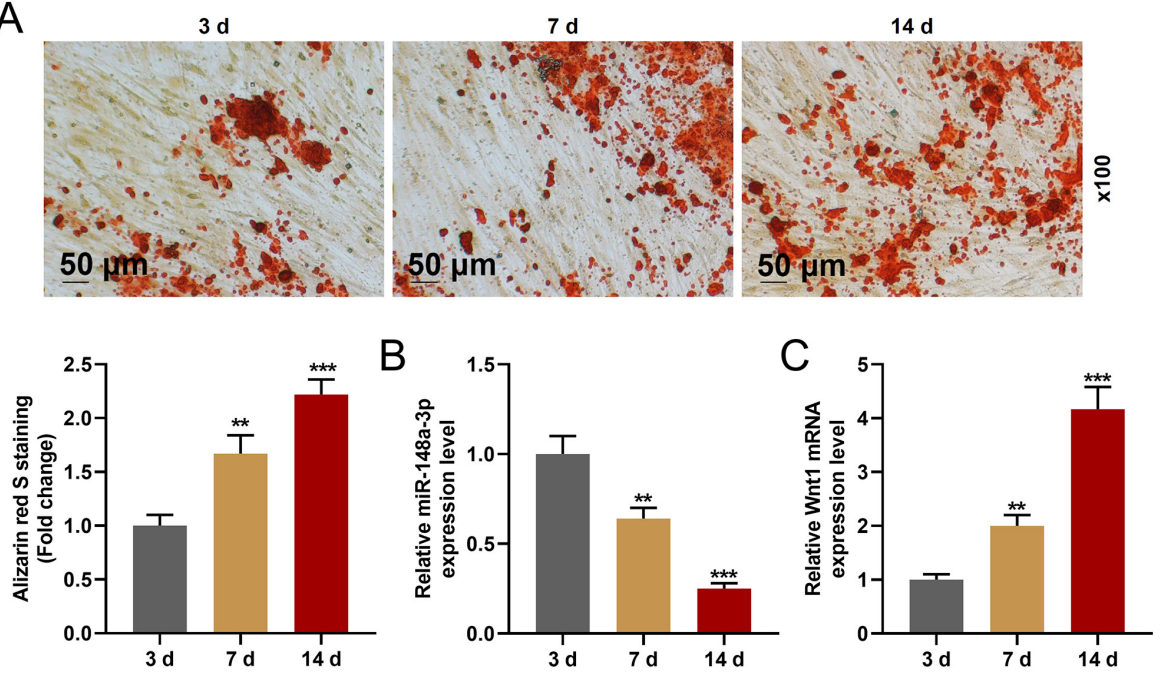

Fig. 2. The expression of miR-148a$3 p$ was decreased and the expression of Wnt1 was increased after the differentiation of hDPSCs. (A) The formation of calcium nodules in hDPSCs after being cultured for 3, 7 and $14 \mathrm{~d}$ was detected by Alizarin red staining. (B) The expression of miR-148a-3p was detected by RTqPCR. U6 used as an internal control. (C) The expression of Wnt1 was detected by RT-qPCR. GAPDH used as an internal control. All experiments were conducted in triplicate $\left({ }^{* *} \mathrm{p}<0.01, * * * \mathrm{p}<0.001\right.$, vs. 3 d) (hDPSCs: human dental pulp stem cells).

both suppressed by miR-148a-3p mimic.

The results also revealed that miR-148a-3p expression was down-regulated (Fig. 2B) and that of Wntl was up-regulated (Fig. 2C) in hDPSCs after the differentiation. All the results indicated that miR-148a-3p and Wntl might play important roles in the differentiation of hDPSCs.

\section{MiR-148a-3p mimic inhibited the viability, invasion, and differentiation of hDPSCs by down-regulating the expressions of DSPP, DMP-1, RUNX2, OCN, and Smad4}

We then transfected miR-148a-3p mimic into hDPSCs (Fig. 3A) to make the role of miR-148a-3p on hDPSCs clear. MTT assay was used to evaluate the effect of miR-148a-3p on the viability of hDPSCs. As shown in Fig. $3 \mathrm{~B}$, the cell viabilities of hDPSCs after being cultured for $3 \mathrm{~d}, 7 \mathrm{~d}$, and $14 \mathrm{~d}$ were significantly decreased by miR-148a-3p mimic. Next, we detected the changes of invasion ability of hDPSCs (Fig. 3C and 3E), the results of which revealed that miR-148a-3p mimic inhibited the invasion rate of hDPSCs. Similarly, the differentiation of hDPSCs was also inhibited by miR-148a-3p mimic (Fig. 3D). DSPP is mainly expressed in odontoblast and closely related to tooth development and biomineralization, and DMP-1 is a non-collagenous extracellular matrix protein of dentin. Therefore, DSPP and DMP-1 are usually used as the markers of odontoblastic differentiation $(19,22,23)$. OCN is one of the differentiation markers from osteoblasts to mineralization stage, and RUNX2 is the key transcription factor for osteogenic differentiation at early stage $(24,25)$. To further verify these results in the molecular level, we detected the expression change of related-factors (Fig. $3 \mathrm{~F} \sim \mathrm{H}$ ), from which we found that the transcription and translation levels of differentiation and invasion key factors (DSPP, DMP-1, RUNX2, OCN, and Smad4) were

\section{MiR-148a-3p specifically targeted Wntl}

From the bioinformatics, Wntl might be targeted by miR-148a-3p (Fig. 4A). Hence, dual-luciferase reporter assays were then performed. As exhibited in Fig. 4B, the luciferase activity was reduced in hDPSCs transfected with miR-148a-3p mimic and Wnt1-WT together. However, after the transfection with miR-148a-3p mimic and PTEN-MUT together, no difference in the luciferase activities was found. Therefore, Wntl could be targeted by miR-148a-3p.

\section{MiR-148a-3p reversed the regulatory effect of Wntl on the cell viability, invasion, and differentiation of hDPSCs}

Then we further infected or transfected Wntl overexpression plasmid, siWnt1, miR-148a-3p mimic or inhibitor into hDPSCs (Fig. 5A and $5 \mathrm{~B}$ ) to investigate the effect of Wntl on hDPSCs and the interaction between Wntl and miR-148a-3p. As depicted in Fig. 5C and 5D, the cell viability was inhibited by miR-148a-3p mimic and siWnt1, while it was enhanced by miR-148a-3p inhibitor and Wntl overexpression. In addition, the effects of siWntl and Wntl overexpression on cell viability could be reversed by miR-148a-3p inhibitor and miR-148a-3p mimic, respectively. Similarly, the invasion (Fig. $5 \mathrm{E} \sim \mathrm{H}$ ) and differentiation (Fig. 5I and 5J) of hDPSCs were also inhibited by miR-148a-3p mimic and siWnt1, whereas they were promoted by miR-148a-3p inhibitor and Wntl overexpression. The effects of siWntl and Wntl overexpression were further reversed by miR-148a-3p inhibitor and $\mathrm{miR}-148 \mathrm{a}-3 \mathrm{p}$ mimic, respectively. 
A

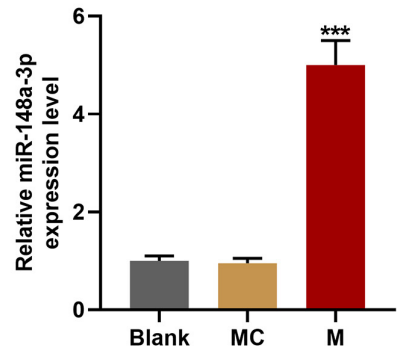

C

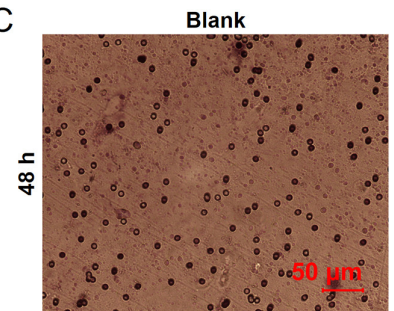

D

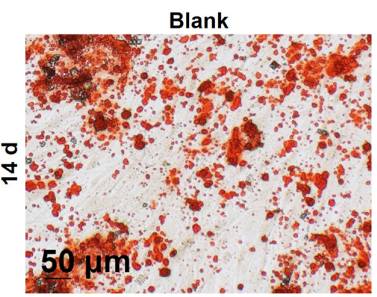

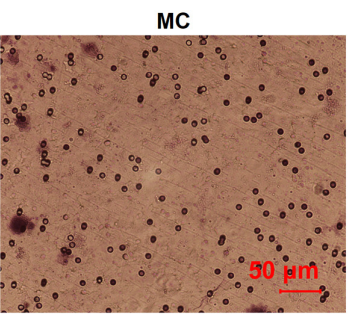

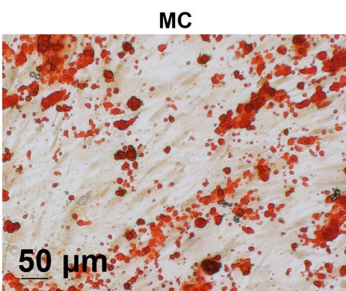

B
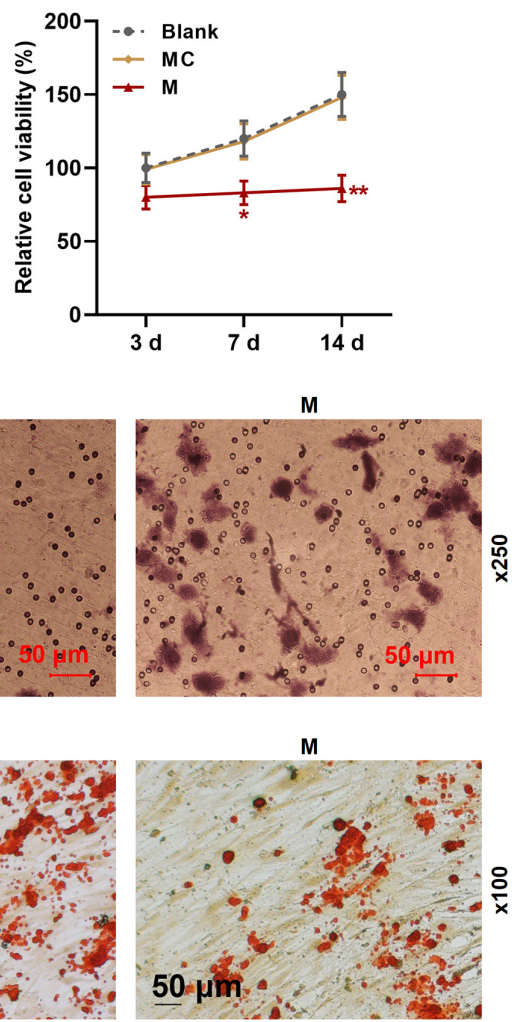
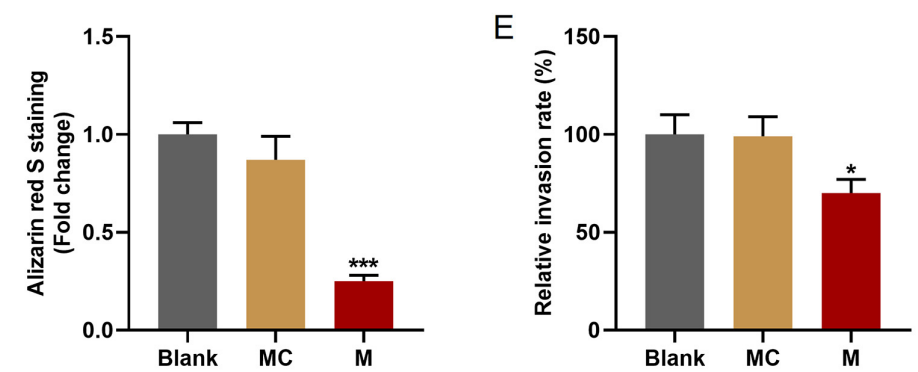

$\mathrm{F}$

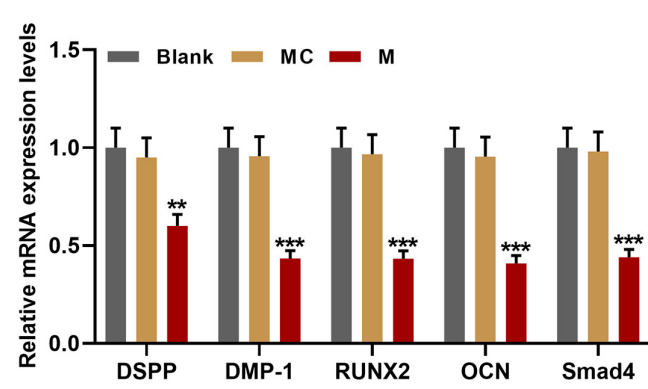

G

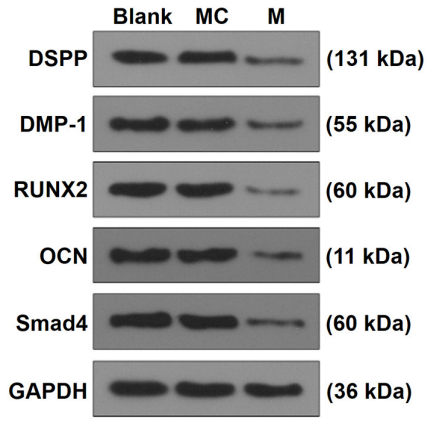

$\mathrm{H}$

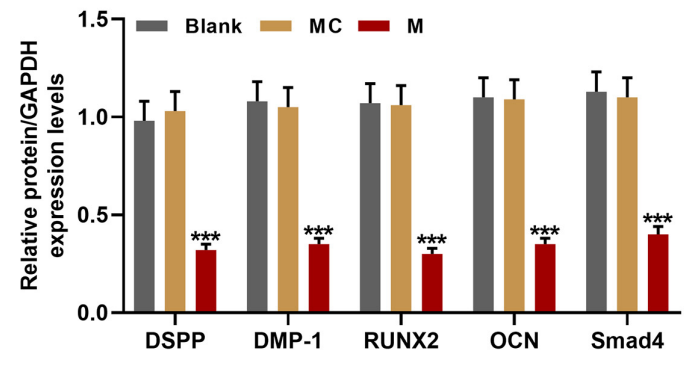

Fig. 3. MiR-148a-3p mimic inhibited the cell viability, invasion, and differentiation of hDPSCs by down-regulating the expressions of DSPP, DMP-1, RUNX2, OCN, and Smad4. (A) The transfection efficiency of miR-148a-3p mimic was detected by RT-qPCR. U6 was used as an internal control. (B) The cell viability of hDPSCs was detected by MTT assays. (C, E) The invasion of hDPSCs was detected by Transwell assays. (D) The formation of calcium nodules in hDPSCs after being cultured for 14 days was detected by Alizarin red staining. (F) The expressions of DSPP, DMP-1, RUNX2, $\mathrm{OCN}$, and Smad4 in hDPSCs were detected by RT-qPCR. GAPDH was used as an internal control. $(\mathrm{G}, \mathrm{H})$ The protein expressions of DSPP, DMP-1, RUNX2, OCN, and Smad4 in hDPSCs were detected by Western blot. GAPDH was used as an internal control. All experiments were conducted in triplicate $\left({ }^{*} p<\right.$ $0.05, * * p<0.01, * * * p<0.001$, vs. MC) (hDPSCs: human dental pulp stem cells, MC: mimic control, M: miR-148a-3p mimic). 

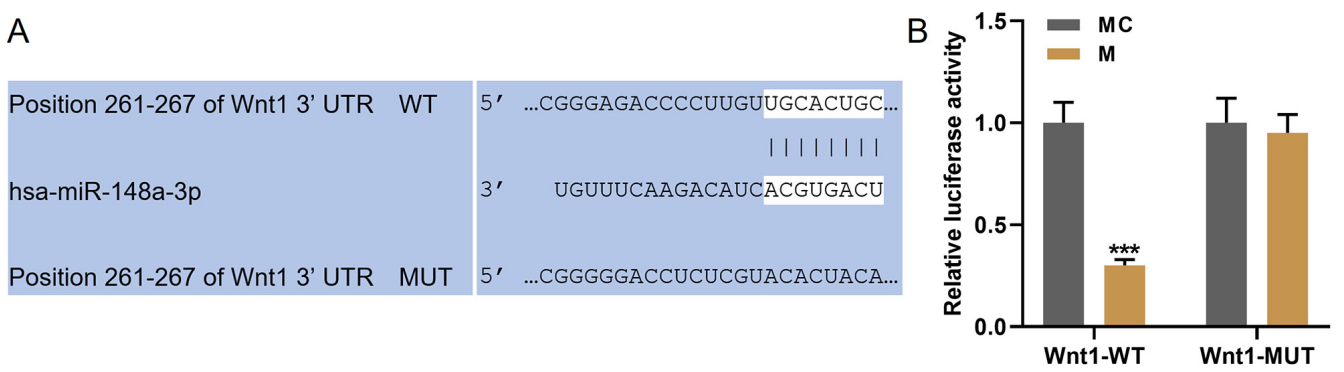

Fig. 4. MiR-148a-3p specifically targets Wnt1. (A) Wnt1-3'-UTR contains a binding site of miR-148a-3p. (B) Dual-luciferase reporter assay validated that miR-148a-3p targeted Wnt1 in hDPSCs. Luciferase from firefly was used as reporter gene and luciferase from sea kidney as internal reference gene. All experiments were conducted in triplicate $(* * * p<0.001$, vs. MC) (hDPSCs: human dental pulp stem cells, MC: mimic control, M: miR-148a-3p mimic).

\section{MiR-148a-3p reversed the regulatory effect of Wntl on the activation of Wntl/ $\beta$-catenin and the expressions of DSPP, DMP-1, RUNX2, OCN, and Smad4}

We finally detected the expression changes of Wnt1, $\beta$ -catenin, DSPP, DMP-1, RUNX2, OCN, and Smad4. As exhibited in Fig. 6A and 6B, the genes expressions of Wnt1, $\beta$-catenin, DSPP, DMP-1, RUNX2, OCN, and Smad4 were inhibited by miR-148a-3p mimic and siWntl, which were increased by miR-148a-3p inhibitor and Wnt1 overexpression. In addition, the regulatory effects of Wnt1 overexpression and siWntl were reversed by miR-148a-3p mimic and inhibitor respectively. As for the protein expressions of these factors (Fig. $6 \mathrm{C} \sim \mathrm{F}$ ), miR-148a-3p mimic and siWntl down-regulated the expressions of Wnt1, $\beta$ -catenin, DSPP, DMP-1, RUNX2, OCN, and Smad4, while miR-148a-3p inhibitor and Wntl overexpression up-regulated the expressions of these factors. In addition, the regulatory effects of Wntl overexpression and siWntl were offset by miR-148a-3p mimic and inhibitor respectively.

\section{Discussion}

In this study, we firstly found that miR-148a-3p expression level was decreased with the odontoblastic differentiation of hDPSCs. Based on this finding, we further found that the up-regulation of miR-148a-3p suppressed the cell viability, invasion, odontoblastic differentiation of hDPSCs by regulating the expressions of related-factors. Then, Wntl was verified as a target gene of miR-148a-3p. In addition, Wntl expression level was increased with the odontoblastic differentiation of hDPSCs, and Wntl knockdown had the regulatory effect similar to miR-148a-3p. What's more, the effect of Wntl could be offset by miR-148a-3p. Our study revealed that miR-148a-3p regulated the invasion and odontoblastic differentiation of hDPSCs.
hDPSCs is capable to be strongly proliferated and differentiated (6). In addition, their clinical application can be attributed to their simple and convenient isolation and culture, lack of ethical controversy and low immunogenicity, which therefore make them as the therapeutic target for the application as autogenous transplantation for pulp and periodontal tissue regeneration $(7,8)$. However, the regulation mechanism of hDPSCs differentiation is still unclear and needed more researches. MiR-148a-3p, a number of the miR-148 family, is located in humans on chromosome 7 and in mouse on chromosome 6, and increasing researches have reported the abnormal expression of miR-148a-3p in different types of diseases $(15,26-28)$. In this study, we found that the expression of miR-148a-3p was significantly decreased with the odontoblastic differentiation of hDPSCs. It was also reported that miR-148a-3p was involved in the cell proliferation, apoptosis, invasion of a series of cells in many diseases $(15,17,26-28)$. In addition, miR-148a-3p regulates the differentiation of the marrow stromal cells into osteoblast (18). In consistent with the previously studies, we found that up-regulated miR-148a-3p suppressed the cell viability, invasion, and odontoblastic differentiation of hDPSCs, and miR-148a-3p knockdown did the opposite. Considering the regulation on the invasion and differentiation of cells was directly regulated by the invasion-related and differentiation-related factors, and the invasion and differentiation level could be indirectly showed in the expressions of related makers $(2,29,30)$. In order to further verify the results in the molecular level in our current study, we further detected the markers of differentiation and invasion, and discovered that miR148a-3p overexpression down-regulated the expressions of DSPP, DMP-1, RUNX2, OCN, and Smad4, whereas miR-148a-3p knockdown up-regulated the expressions of these factors, which further proved that miR-148a-3p had 

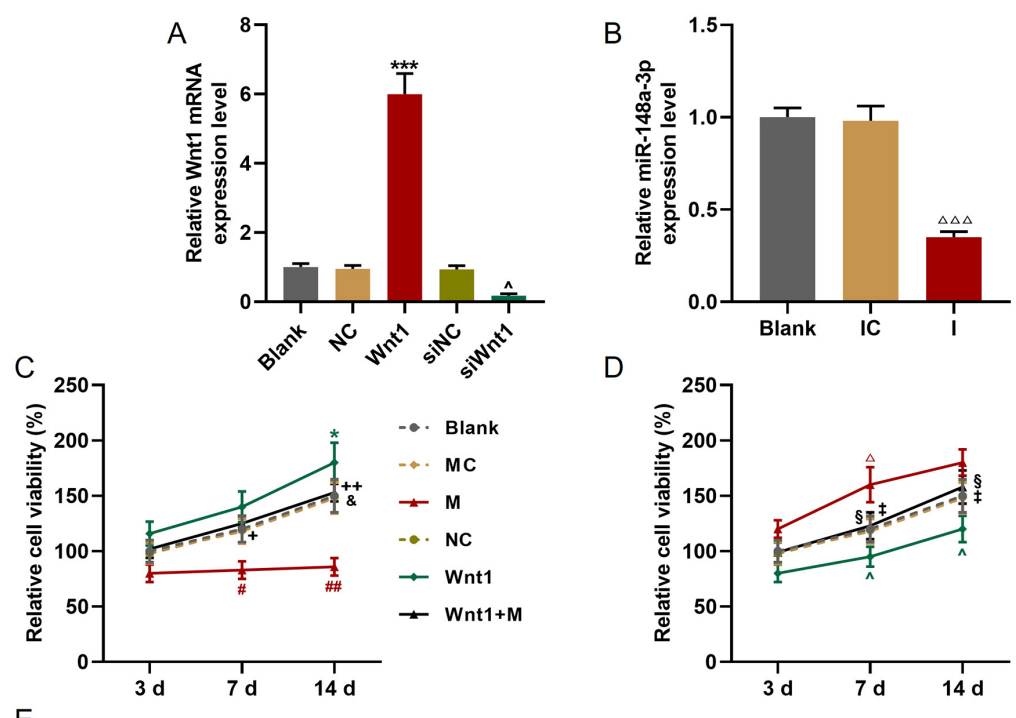

D
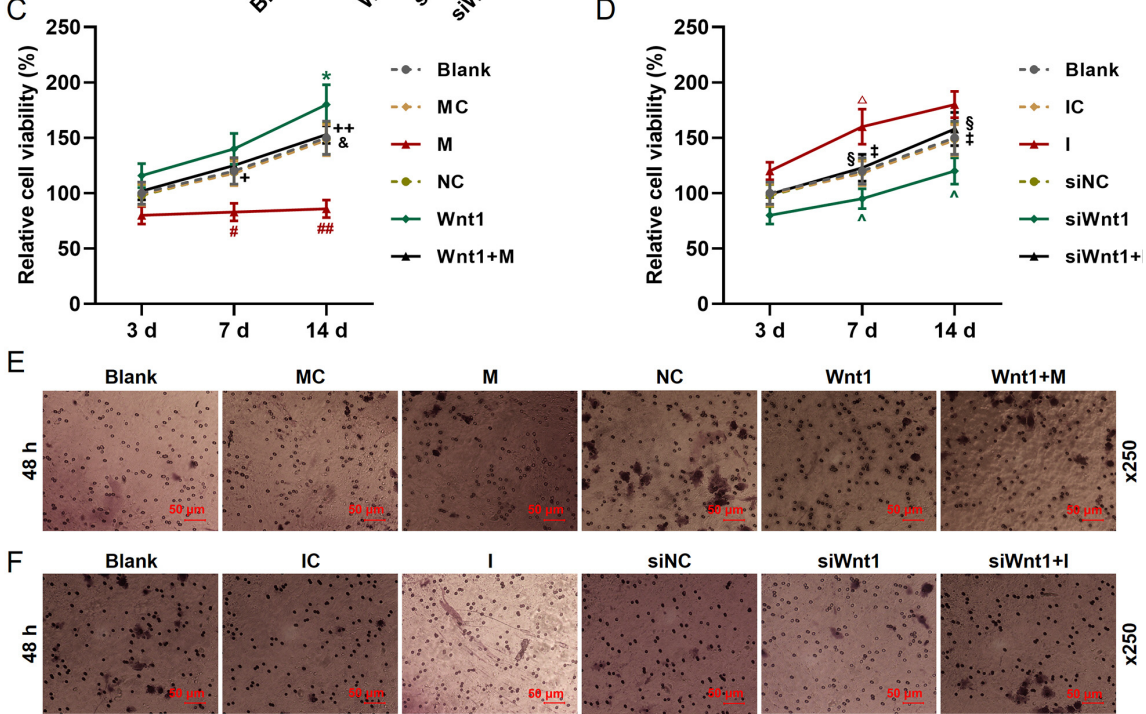

IC

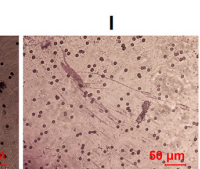

siNC

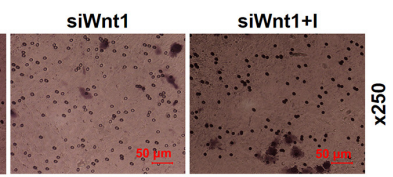

G
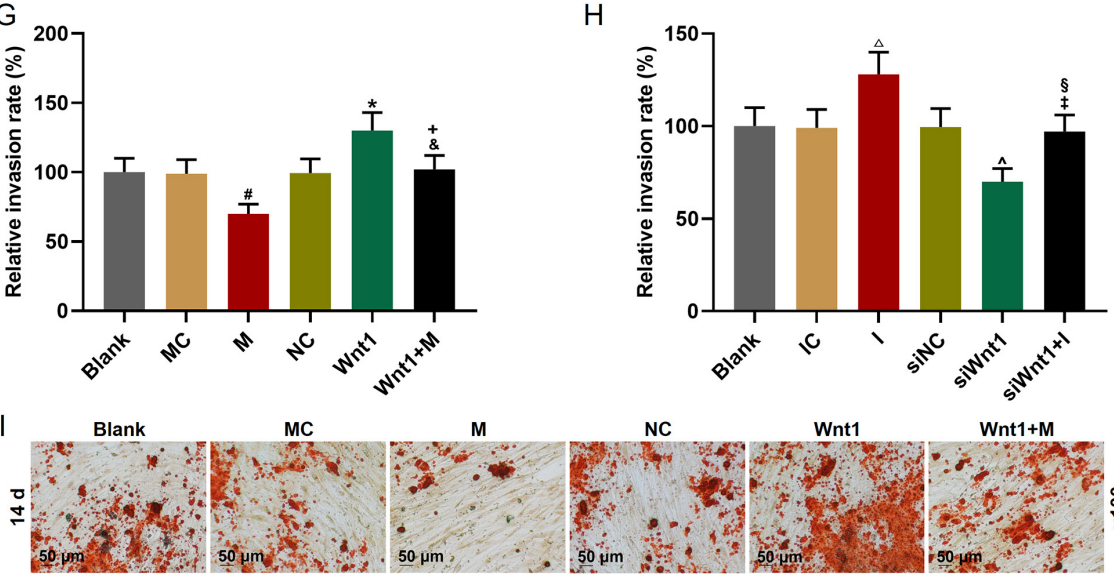

NC

Wnt1

Wnt1+M
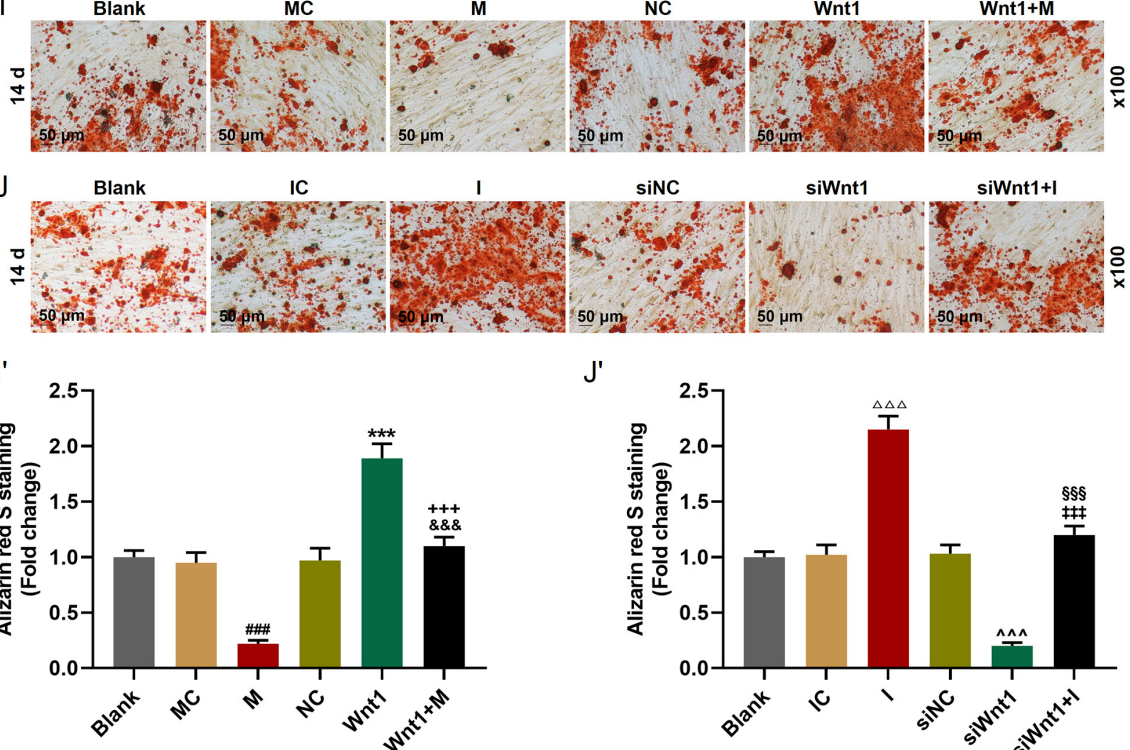

siNC siWnt1

siWnt1+1
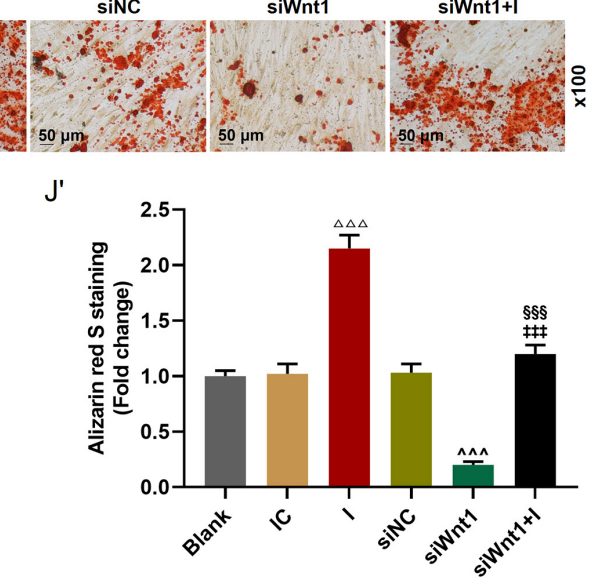

Fig. 5. MiR-148a-3p reversed the regulatory effect of Wnt1 on the cell viability, invasion, and differentiation of hDPSCs. (A) Infection efficiency of Wnt1 and siWnt1 was detected by RT-qPCR. GAPDH was used as an internal control. (B) Transfection efficiency of miR-148a-3p inhibitor was detected by RT-qPCR. U6 was used as an internal control. (C, D) The cell viability of hDPSCs was detected by MTT assays. $(\mathrm{E} \sim \mathrm{H})$ The invasion of hDPSCs was detected by Transwell assays. (I, J) The formation of calcium nodules in hDPSCs was detected by Alizarin red staining. All experiments were conducted in triplicate $\quad\left({ }^{*} \mathrm{p}<0.05, \quad * * \mathrm{p}<0.01, \quad * * * \mathrm{p}<\right.$ 0.001 , vs. NC; $\hat{p}<0.05$, $\mu_{\mathrm{p}}<0.01$, vs. siNC; ${ }^{\#} p<0.05,{ }^{\#} p<0.01,{ }^{\# \#} p<0.001$, vs. MC; ${ }_{p}<0.05,{ }_{p}<0.01$, vs. IC; ${ }^{+} p<$ $0.05,{ }^{++} p<0.01,{ }^{+++} p<0.001$, vs. $M{ }^{\&}{ }^{\&}<$ $0.05,{ }^{\& \&} \mathrm{p}<0.01$, vs. Wht1; ${ }^{\S_{p}}<0.05,{ }^{\S \S} \mathrm{p}<$ 0.01 , vs. I; ${ }^{\ddagger} \mathrm{p}<0.05$, ${ }^{\neq \neq} \mathrm{p}<0.01$, vs. siWnt1) (hDPSCs: human dental pulp stem cells, NC: negative control, siNC: small interfering RNA for negative control, MC: mimic control, IC: inhibitor control, M: miR-148a$3 p$ mimic, I: miR-148a-3p inhibitor). 

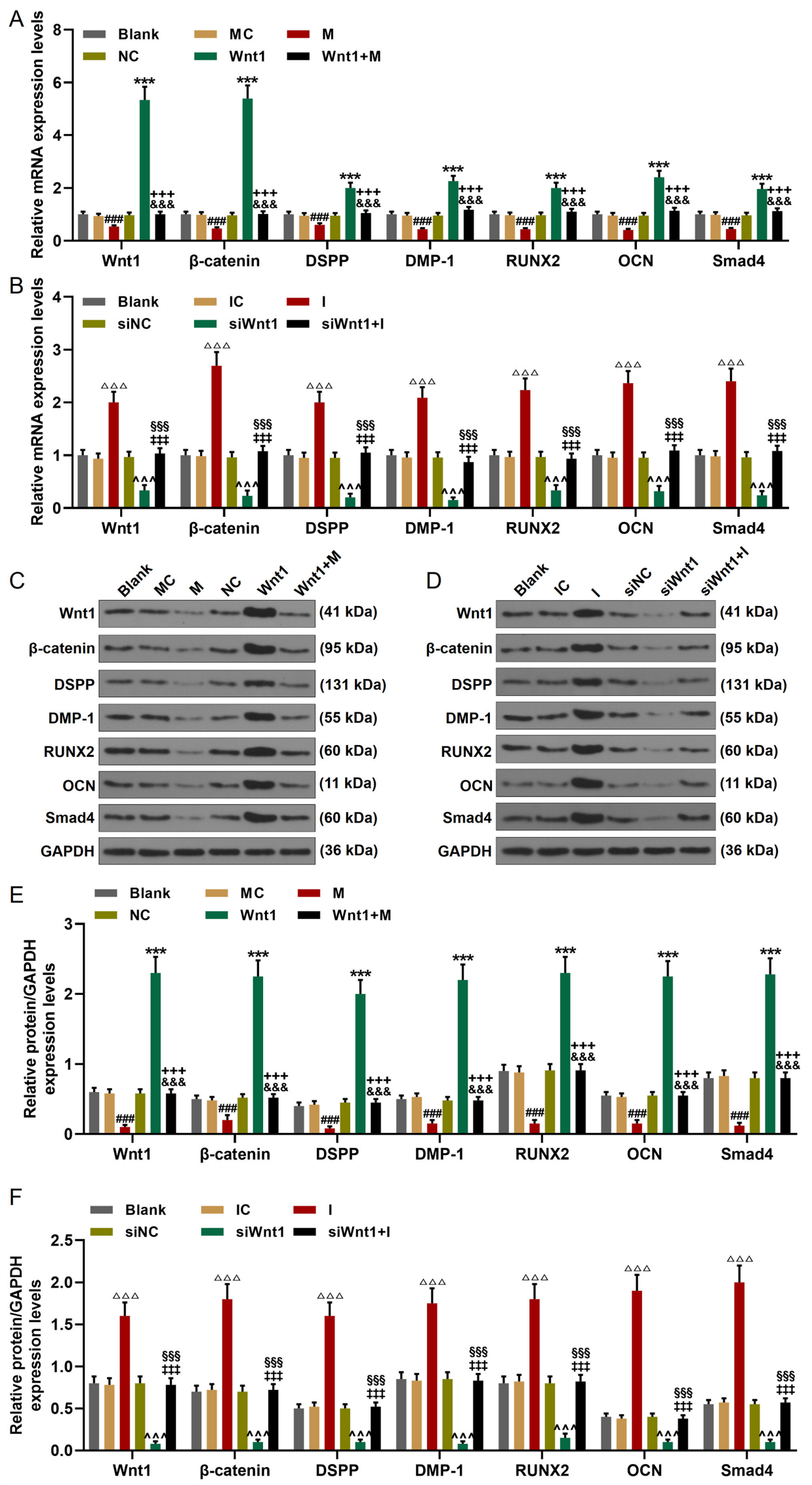

Fig. 6. MiR-148a-3p reversed the regulatory effect of Wnt1 on the activation of $W n t 1 / \beta$-catenin and the expressions of DSPP, DMP-1, RUNX2, OCN, and Smad4. (A, B) The expressions of Wnt1, $\beta$-catenin, DSPP, DMP-1, RUNX2, OCN, and Smad4 in hDPSCs were detected by RT-qPCR. GAPDH was used as an internal control. $(\mathrm{C} \sim \mathrm{F})$ The protein expressions of Wnt1, $\beta$ -catenin, DSPP, DMP-1, RUNX2, OCN, and Smad4 in hDPSCs were detected by Western blot. GAPDH was used as an internal control. All experiments were conducted in triplicate ${ }^{* * *} \mathrm{p}<0.001$, vs. NC; ${ }^{\wedge}{ }^{\wedge} \mathrm{p}<$ 0.001 , vs. siNC; ${ }^{\# \#} \mathrm{p}<0.001$, vs. MC; $\triangle \Delta \triangle \mathrm{p}<0.001$, vs. IC; ${ }^{+++} \mathrm{p}<0.001$, vs. $M ;{ }^{\& \& \&} p<0.001$, vs. Wnt1; ${ }^{\$ \$ S} \mathrm{p}<$ 0.001 , vs. l; ${ }^{\ddagger \ddagger} \mathrm{p}<0.001$, vs. siWnt1) (hDPSCs: human dental pulp stem cells, NC: negative control, siNC: small interfering RNA for negative control, MC: mimic control, IC: inhibitor control, M: miR-148a-3p mimic, I: miR-148a-3p inhibitor). 
the capacity to regulate the invasion and odontoblastic differentiation of hDPSCs.

Accumulating evidence had confirmed that miRNAs could target some certain mRNA and further regulate the development of a variety of diseases (5, 13, 30). Many mRNAs could be targeted by miR-148a-3p during the regulation of miR-148a-3p on biological functions of different types of cells. For example, miR-148a-3p targeted c-Met to inhibit the progression of epithelial ovarian cancer (31). KLF6 was targeted by miR-148a-3p to regulate the proliferation of bovine muscle cells (32). Wnt/ $\beta$-catenin axis was modulated by miR-148a-3p to promote the proliferation and invasion of ovarian cells (16). In addition, Wntl was also reported to be involved in the odontoblastic differentiation of hDPSCs (2). The Wntl/ $\beta$-catenin signaling pathway is involved in regulating the physiological process of hDPSCs, but the role of miRNAs in regulating the physiological process of hDPSCs via Wntl/ $\beta$-catenin signaling pathway is rarely studied. Therefore, we wonder whether Wntl could be targeted by miR-148a-3p in the odontoblastic differentiation of hDPSCs. To our delight, the results in this study not only showed that the expression of Wntl was increased with the odontoblastic differentiation of hDPSCs but also verified that Wntl could be targeted by miR-148a-3p in hDPSCs. In addition, the cell viability, invasion and odontoblastic differentiation could be promoted by Wntl overexpression and inhibited by Wnt1 knockdown. In addition, the regulatory effect of Wnt1 on hDPSCs could be reversed by miR-148a-3p, which confirmed that miR-148a-3p regulated the invasion and odontoblastic differentiation by targeting Wntl. Wntl belongs to the Wnt family, and the classical Wnt/ $\beta$ -catenin pathway plays an important role in the organ formation, tissue regeneration, and other physiological processes $(2,33)$. Furthermore, Wntl/ $\beta$-catenin pathway was widely reported to be involved in many physiological processes, including cell proliferation, fibrosis, and differentiation (34-37). Furthermore, a research had reported Wntl/ $\beta$-catenin pathway was involved in the odontoblastic differentiation of hDPSCs and could be regulated by miR-140-5p (2). Similarly, our results exhibited that the expression of $\beta$-catenin in hDPSCs was up-regulated by Wnt1 overexpression and miR-148a-3p knockdown, while it was down-regulated by Wntl knockdown and miR-148a-3p overexpression, suggesting that the effect of Wnt1 on the expression of $\beta$-catenin was further reversed by miR-148a-3p. All these results revealed that the effect of miR-148a-3p on invasion and odontoblastic differentiation of hDPSCs was mediated by targeting Wntl/ $\beta$ -catenin pathway. It has been reported that stathmin pro- motes the proliferation and odontoblastic/osteogenic differentiation of hDPSCs through activating the Wnt/ $\beta$ -catenin signaling pathway (38). The activation of $\mathrm{Wnt} / \beta$ -catenin signaling pathway promotes the odontogenic differentiation of dental pulp stem cells $(21,39)$. However, Scheller et al. (40) reported that Wnt/ $\beta$-catenin signaling pathway inhibits the differentiation of DPSCs. The Wnt/ $\beta$-catenin pathway has different effects on the differentiation of hDPSCs, and the causes for these differences need to be further investigated.

In a word, the results in this study revealed that miR-148a-3p regulated the viability, invasion and odontoblastic differentiation of hDPSCs via regulating Wntl/ $\beta$ -catenin pathway.

\section{Acknowledgments}

Not applicable.

\section{Potential Conflict of Interest}

The authors have no conflicting financial interest.

\section{References}

1. Alsaeedi HA, Lam C, Koh AE, Teh SW, Mok PL, Higuchi A, Then KY, Bastion MC, Alzahrani B, Farhana A, Muthuvenkatachalam BS, Samrot AV, Swamy KB, Marraiki N, Elgorban AM, Subbiah SK. Looking into dental pulp stem cells in the therapy of photoreceptors and retinal degenerative disorders. J Photochem Photobiol B 2020;203: 111727

2. Lu X, Chen X, Xing J, Lian M, Huang D, Lu Y, Feng G, Feng X. miR-140-5p regulates the odontoblastic differentiation of dental pulp stem cells via the Wntl/ $\beta$-catenin signaling pathway. Stem Cell Res Ther 2019;10:226

3. Mirhosseini M, Shiari R, Esmaeili Motlagh P, Farivar S. Cerebrospinal fluid and photobiomodulation effects on neural gene expression in dental pulp stem cells. J Lasers Med Sci 2019;10(Suppl 1):S30-S36

4. Wang W, Yuan C, Geng T, Liu Y, Zhu S, Zhang C, Liu $Z$, Wang P. EphrinB2 overexpression enhances osteogenic differentiation of dental pulp stem cells partially through ephrinB2-mediated reverse signaling. Stem Cell Res Ther 2020;11:40

5. Qiao W, Li D, Shi Q, Wang H, Wang H, Guo J. miR-224$5 p$ protects dental pulp stem cells from apoptosis by targeting Rac1. Exp Ther Med 2020;19:9-18

6. Luke AM, Patnaik R, Kuriadom S, Abu-Fanas S, Mathew S, Shetty KP. Human dental pulp stem cells differentiation to neural cells, osteocytes and adipocytes-an in vitro study. Heliyon 2020;6:e03054

7. Bu NU, Lee HS, Lee BN, Hwang YC, Kim SY, Chang SW, Choi KK, Kim DS, Jang JH. In vitro characterization of dental pulp stem cells cultured in two microsphere-forming 
culture plates. J Clin Med 2020;9:242

8. Kamel AHM, Kamal SM, AbuBakr N. Effect of smoking on the proliferation capacity and osteogenic potential of human dental pulp stem cells (DPSCs). Dent Med Probl 2020;57:19-24

9. Kim Y, Park JY, Park HJ, Kim MK, Kim YI, Kim HJ, Bae SK, Bae MK. Pentraxin-3 modulates osteogenic/odontogenic differentiation and migration of human dental pulp stem cells. Int J Mol Sci 2019;20:5778

10. Liang H, Li W, Yang H, Cao Y, Ge L, Shi R, Fan Z, Dong $\mathrm{R}$, Zhang C. FAM96B inhibits the senescence of dental pulp stem cells. Cell Biol Int 2020;44:1193-1203

11. Vishnoi A, Rani S. MiRNA biogenesis and regulation of diseases: an overview. Methods Mol Biol 2017;1509:1-10

12. Xiaobing T, Qingyuan D. [Characterization of microRNAs profiles of induced pluripotent stem cells reprogrammed from human dental pulp stem cells and stem cells from apical papilla]. Hua Xi Kou Qiang Yi Xue Za Zhi 2017;35:269-274. Chinese

13. Wang J, Zheng Y, Bai B, Song Y, Zheng K, Xiao J, Liang Y, Bao L, Zhou Q, Ji L, Feng X. MicroRNA-125a-3p participates in odontoblastic differentiation of dental pulp stem cells by targeting Fyn. Cytotechnology 2020;72:69-79

14. Ke Z, Qiu Z, Xiao T, Zeng J, Zou L, Lin X, Hu X, Lin $\mathrm{S}, \mathrm{Lv}$ H. Downregulation of miR-224-5p promotes migration and proliferation in human dental pulp stem cells. Biomed Res Int 2019;2019:4759060

15. Cai SW, Han Y, Wang GP. miR-148a-3p exhaustion inhibits necrosis by regulating PTEN in acute pancreatitis. Int J Clin Exp Pathol 2018;11:5647-5657

16. Pan L, Meng Q, Li H, Liang K, Li B. LINC00339 promotes cell proliferation, migration, and invasion of ovarian cancer cells via miR-148a-3p/ROCK1 axes. Biomed Pharmacother 2019;120:109423

17. Song B, Du J, Song DF, Ren JC, Feng Y. Dysregulation of NCAPG, KNL1, miR-148a-3p, miR-193b-3p, and miR-1179 may contribute to the progression of gastric cancer. Biol Res 2018;51:44

18. Yuan H, Xu X, Feng X, Zhu E, Zhou J, Wang G, Tian L, Wang B. A novel long noncoding RNA PGC1 $\beta$-OT1 regulates adipocyte and osteoblast differentiation through antagonizing miR-148a-3p. Cell Death Differ 2019;26:20292045

19. Chen M, Yang Y, Zeng J, Deng Z, Wu B. circRNA expression profile in dental pulp stem cells during odontogenic differentiation. Stem Cells Int 2020;2020:5405931

20. Labedz-Maslowska A, Bryniarska N, Kubiak A, Kaczmarzyk T, Sekula-Stryjewska M, Noga S, Boruczkowski D, Madeja Z, Zuba-Surma E. Multilineage differentiation potential of human dental pulp stem cells-impact of 3D and hypoxic environment on osteogenesis in vitro. Int J Mol Sci 2020; 21:6172

21. Gong Y, Yuan S, Sun J, Wang Y, Liu S, Guo R, Dong W, Li R. R-Spondin 2 induces odontogenic differentiation of dental pulp stem/progenitor cells via regulation of $\mathrm{Wnt} / \beta$ -catenin signaling. Front Physiol 2020;11:918
22. Kim YJ, Kim WJ, Bae SW, Yang SM, Park SY, Kim SM, Jung JY. Mineral trioxide aggregate-induced AMPK activation stimulates odontoblastic differentiation of human dental pulp cells. Int Endod J 2021;54:753-767

23. Li S, Lin C, Zhang J, Tao H, Liu H, Yuan G, Chen Z. Quaking promotes the odontoblastic differentiation of human dental pulp stem cells. J Cell Physiol 2018;233:72927304

24. Feng G, Zhang J, Feng X, Wu S, Huang D, Hu J, Zhu S, Song D. Runx2 modified dental pulp stem cells (DPSCs) enhance new bone formation during rapid distraction osteogenesis (DO). Differentiation 2016;92:195-203

25. Xin $\mathrm{BC}$, Wu QS, Jin S, Luo AH, Sun DG, Wang F. Berberine promotes osteogenic differentiation of human dental pulp stem cells through activating EGFR-MAPKRunx2 pathways. Pathol Oncol Res 2020;26:1677-1685

26. Friedrich M, Pracht K, Mashreghi MF, Jäck HM, Radbruch A, Seliger B. The role of the miR-148/-152 family in physiology and disease. Eur J Immunol 2017;47:20262038

27. Zeng J, Zhu L, Liu J, Zhu T, Xie Z, Sun X, Zhang H. Metformin protects against oxidative stress injury induced by ischemia/reperfusion via regulation of the lncRNAH19/miR-148a-3p/Rock2 axis. Oxid Med Cell Longev 2019; 2019:8768327

28. Dybos SA, Flatberg A, Halgunset J, Viset T, Rolfseng T, Kvam S, Skogseth H. Increased levels of serum miR-148a$3 p$ are associated with prostate cancer. APMIS 2018;126: $722-731$

29. Liu F, Wang X, Yang Y, Hu R, Wang W, Wang Y. The suppressive effects of miR-508-5p on the odontogenic differentiation of human dental pulp stem cells by targeting glycoprotein non-metastatic melanomal protein B. Stem Cell Res Ther 2019;10:35

30. Zhan FL, Liu XY, Wang XB. The role of MicroRNA-143$5 p$ in the differentiation of dental pulp stem cells into odontoblasts by targeting Runx2 via the OPG/RANKL signaling pathway. J Cell Biochem 2018;119:536-546

31. Wang W, Dong J, Wang M, Yao S, Tian X, Cui X, Fu S, Zhang S. miR-148a-3p suppresses epithelial ovarian cancer progression primarily by targeting c-Met. Oncol Lett 2018; 15:6131-6136

32. Song C, Yang J, Jiang R, Yang Z, Li H, Huang Y, Lan X, Lei C, Ma Y, Qi X, Chen H. miR-148a-3p regulates proliferation and apoptosis of bovine muscle cells by targeting KLF6. J Cell Physiol 2019 [Epub ahead of print]

33. Tang Y, Yang P, Zhu Y, Su Y. LncRNA TUG1 contributes to ESCC progression via regulating miR-148a-3p/MCL-1/ Wnt/ $\beta$-catenin axis in vitro. Thorac Cancer 2020;11:82-94

34. Huang L, Ying $\mathrm{H}$, Chen Z, Zhu YL, Gu Y, Hu L, Chen D, Zhong N. Down-regulation of DKKl and Wntl/ $\beta$ -catenin pathway by increased homeobox B7 resulted in cell differentiation suppression of intrauterine fetal growth retardation in human placenta. Placenta 2019;80:27-35

35. Song P, Zheng JX, Liu JZ, Xu J, Wu LY, Liu C, Zhu Q, Wang Y. Effect of the Wntl/ $\beta$-catenin signalling pathway 
on human embryonic pulmonary fibroblasts. Mol Med Rep 2014;10:1030-1036

36. Zhang C, Hao Y, Sun Y, Liu P. Quercetin suppresses the tumorigenesis of oral squamous cell carcinoma by regulating microRNA-22/WNT1/ $\beta$-catenin axis. J Pharmacol Sci 2019;140:128-136

37. Zhang JG, Shi Y, Hong DF, Song M, Huang D, Wang CY, Zhao G. MiR-148b suppresses cell proliferation and invasion in hepatocellular carcinoma by targeting $\mathrm{WNT1} / \beta$ catenin pathway. Sci Rep 2015;5:8087

38. Zhang X, Ning T, Wang H, Xu S, Yu H, Luo X, Hao C, Wu B, Ma D. Stathmin regulates the proliferation and odontoblastic/osteogenic differentiation of human dental pulp stem cells through Wnt/ $\beta$-catenin signaling pathway. J Proteomics 2019;202:103364

39. Ali M, Okamoto M, Komichi S, Watanabe M, Huang H, Takahashi Y, Hayashi M. Lithium-containing surface pre-reacted glass fillers enhance hDPSC functions and induce reparative dentin formation in a rat pulp capping model through activation of Wnt $/ \beta$-catenin signaling. Acta Biomater 2019;96:594-604

40. Scheller EL, Chang J, Wang CY. Wnt/beta-catenin inhibits dental pulp stem cell differentiation. J Dent Res 2008;87: 126-130 